\title{
A IMPORTÂNCIA DA OBSERVAÇÃO DE AULAS NO PROCESSO DE AVALIAÇÃO DE DESEMPENHO DOCENTE: CONCEÇÕES DE PROFESSORES
}

\section{Maria Deolinda Oliveira Silva*}

Resumo: Vivemos, hoje, numa sociedade de inquietação, modificações constantes e diversidade cultural.

Em Portugal, recentemente, a Avaliação do Desempenho dos Docentes sofreu alterações que obrigaram a regulamentação própria. Assim, passou-se para um sistema mais complexo, onde o número de fontes e de instrumentos de avaliação aumentou, com a finalidade de se garantir, para além da promoção e progressão na carreira, o desenvolvimento profissional do docente e a melhoria dos resultados escolares dos alunos.

Neste contexto, a sociedade exige aos professores que façam da escola um espaço atrativo onde seja possivel motivar os alunos para a aprendizagem.

Estimular a melhoria do desempenho profissional impõe uma atitude de corresponsabilização entre os pares, as instituições que estes integram e o público-alvo com quem interagem no quotidiano escolar.

Então, neste contexto, supervisão é, fundamentalmente, interagir, informar, questionar, sugerir, encorajar $e$ avaliar. (Alarcão $e$ Tavares, 2003).

Assim sendo, a avaliação de desempenho docente é uma área de atual interesse. Deste modo, sentiu-se a necessidade de aprofundar esta temática, beneficiando do contato de quem lida diretamente com ela, procurando saber se concorda ou discorda desta e, perceber os motivos pelos quais os docentes se debatem e o que sugerem para que esta possa ser melhorada.

Este trabalho pretende, assim, apresentar a opinião de alguns professores sobre o atual modelo da Avaliação do Desempenho Docente; Identificar pontos fortes e fracos no atual modelo de Avaliação do Desempenho Docente e conhecer a importância da

\footnotetext{
* Professora de Educação Especial Licenciada em Humanidades pela Universidade Católica Portuguesa, Centro Regional das Beiras -Viseu. Formação Especializada em Educação Especial. Mestre em Ciências da Educação - Educação Especial. Especialista em Supervisão Pedagógica e Avaliação de Desempenho Docente.
} 
observação de aulas no processo de Avaliação de Desempenho Docente.

O estudo empírico decorreu num agrupamento de escolas do Concelho de Viseu.

Como principais conclusões podemos destacar que a avaliação deve ser realizada e analisada por uma equipa especializada. Que a observação de aulas deverá constituir um processo colaborativo entre o professor e o mentor ou supervisor. Ambos devem desempenhar papéis importantes - antes, durante e após a observação, de forma a assegurar benefícios mútuos no desenvolvimento pessoal e profissional; a avaliação obriga a refletir sobre o que se faz.

É fundamental destacar o facto de os professores referirem que a formação especializada em supervisão pedagógica e avaliação de desempenho docente é o mais urgente, neste momento.

Palavras-Chave: Avaliação do Desempenho Docente, Supervisão Pedagógica

\section{INTRODUÇÃO}

O sistema educativo português defronta-se com algumas instabilidades, quer ao nível da atividade docente, que se tem tornado cada vez mais exigente, inconstante e insegura, quer ao nível das verdadeiras expetativas sociais e económicas dos alunos e das suas famílias.

No passado, os elementos integrantes do sistema cumpriam, separadamente, a sua função, ou seja, os alunos aprendiam, os professores ensinavam, os programas orientavam e, no fim, eram encontradas formas adicionais para atribuir graus, interpretar resultados e indicadores de sucesso. A visão moderna de avaliação transformou-a num processo integrado e bastante mais abrangente, indissociável de um vasto conjunto de elementos, que vão desde a definição de objetivos e padrões de referência, passando pelos processos de ensino e de aprendizagem, bem como de desenvolvimento de programas, até à conceção de mecanismos de retorno da informação que permita introduzir correções relativamente ao percurso seguido, para melhor atingir os objetivos pretendidos.

Quando se implementa um modelo de avaliação de desempenho de professores, provavelmente, cria nas escolas alguma confusão, nomeadamente, críticas, desconfianças, medos e ansiedade. Assim sendo, é necessário que as escolas possam pensar, profundamente, sobre a forma como pretendem estruturar a avaliação dos seus professores, antes de iniciarem a construção dos instrumentos de avaliação. Assim, tanto as escolas como os professores, devem usar de critérios de rigor e adequação ética.

O sucesso de uma observação de aula baseia-se na seleção e na adaptação rigorosas dos instrumentos de acordo com o contexto, as fases do ciclo de supervisão, o foco da observação e as necessidades específicas de cada professor. Tanto professores observados como observadores beneficiam da observação e do debate de aulas. 
Uma das competências mais significativas do supervisor é a sua capacidade de observação, pois todos nós, num cenário de supervisão, observamos situações diferentes.

A ADD é uma área de atual interesse. Deste modo, sentiu-se a necessidade de aprofundar esta temática, beneficiando do contato dos que lidam diretamente com a ADD e saber se concordam ou discordam desta, percebendo os motivos pelos quais os docentes se debatem e o que sugerem para que a ADD possa ser melhorada.

Este trabalho pretende, assim, apresentar a opinião de alguns professores sobre o atual modelo da Avaliação do Desempenho Docente; Identificar pontos fortes e fracos no atual modelo de Avaliação do Desempenho Docente e conhecer a importância da observação de aulas no processo de Avaliação de Desempenho Docente. O mesmo é constituído pelos seguintes pontos: $\mathrm{Na}$ primeira parte, referente à fundamentação teórica, abordamos profissionalização e desprofissionalização, a avaliação de desempenho docente, observação de aulas e finalidade da supervisão e da avaliação no contexto de observação de aulas. Na segunda parte, fazemos um breve estudo às conceções sobre a ADD num Agrupamento de escolas do Concelho de Viseu.

\section{PROFESSORES: PROFISSIONALIZAÇÃO VERSUS DESPROFISSIONALIZAÇÃO}

Nos dias de hoje os professores deparam-se com problemas e dificuldades que no passado praticamente não se verificavam, os quais resultam de grandes mudanças operadas na sociedade a nível político, económico, social e cultural. Estas mudanças refletem-se no sistema educacional dificultando a definição de objetivos institucionais e pedagógicos que podem desencadear na classe docente um sentimento de mal-estar.

Conjetura-se que estamos perante um fenómeno em expansão, fortificação e de indefinição quanto ao papel do professor e da escola, o que faz com que os professores estejam na profissão de maneira diferente em comparação entre o seu "antes" e o seu "agora" profissional (Montero, 1999, p. 2).

A partir de uma breve resenha histórica podemos situar momentos determinantes para a profissão docente.

No final do século XVIII, dá-se um passo decisivo para o processo da profissionalização da atividade docente, ao ser necessária uma licença /autorização do Estado para ensinar, através de um exame que obedecia a determinadas condições (habilitações, idade, comportamento moral, etc.), e permitia a definição de um perfil de competências técnicas que ia servir de base ao recrutamento de professores e ao delinear de uma carreira docente (Nóvoa, 1999; Sousa, 2000). 
No início do século XIX, em Portugal, assiste-se a uma mudança no discurso pedagógico em termos de defesa de uma educação que permita o acesso das diferentes classes sociais à escola. Para colocar em prática três linhas de força, sendo elas a escolaridade obrigatória, a gratuitidade e a liberdade do ensino, é necessário ter um corpo pedagógico competente e qualificado (Sousa 2000). Começa assim, a preocupação com a formação profissional dos professores surgindo as primeiras escolas responsáveis pela sua formação (Nóvoa 1999). Mas é na segunda metade do século XIX, que se verifica um momento importante no processo de profissionalização, com a constituição de diferentes associações profissionais de professores que passam a ter um papel importante na defesa do seu estatuto sócio profissional (Loureiro, 2001).

Já no início do século XX, com a primeira Republica, a sociedade confere aos professores um papel de grande relevância, uma vez que toma consciência do papel fundamental que os professores têm enquanto marcos determinantes no progresso de um país (Sousa, 2000).

Também Nóvoa (1999) salienta que o inicio do século XX, "é o período de ouro da profissão docente" pois os professores têm um papel de grande relevo enquanto agentes de desenvolvimento da escola e da instrução (p.9). Contudo, a grande explosão na profissionalização dos professores só ocorre no pós 25 de Abril. A formação dos professores do primeiro ciclo é reformulada passando a haver maior articulação entre a formação e a própria realidade. No ensino secundário, os estágios passam a ser da responsabilidade das escolas, onde se assiste à organização de ações de formação e de reflexão pedagógica (Fontes, s.d.).

Em 1979, implementa-se a formação em exercício que alguns anos depois (1988) é substituída pela profissionalização em serviço. Estas modalidades tiveram como objetivo proporcionar a profissionalização a todos os professores que já estavam vinculados ao Ministério da Educação.

Nos anos noventa, estavam resolvidos os problemas de profissionalização dos professores e as atenções voltam-se para a formação contínua. Este processo ganha importância pois dele depende a qualificação dos professores para o desempenho de novas funções que lhes são exigidas tais como administração e gestão escolar e profissional (Nóvoa, 1997).

Segundo Alarcão (2001), esta foi uma etapa importante, no caminho da profissionalização dos professores, porque aparece após um período de vivência de sentimento de perda de identidade profissional e vem permitir a diminuição do isolamento profissional, efeito do trabalho em equipa, utilização de uma linguagem profissional cada vez mais própria, consciência da necessidade de formação contínua, aumento da responsabilidade do professor na gestão do currículo e uma maior interação com a comunidade educativa.

A partir das últimas três décadas do século $\mathrm{XX}$, a escola portuguesa acompanhou um ritmo de transformações sociais, políticas, económicas e culturais, que ao nível do ensino se traduziram numa crescente complexidade 
de funções atribuídas aos professores no sentido de abrir a escola ao mundo da modernidade.

Para além da crescente complexidade da função docente, a massificação do ensino também arrastou consigo a massificação dos professores, trazendo a esta classe profissional repercussões ao nível do estatuto e das condições de trabalho nas escolas, conduzindo a uma degradação da profissão docente e a uma crise de identidade profissional (Cunha, 2008).

A perda de prestígio da profissão docente está, assim, associada ao facto de esta se apresentar pouco seletiva, exercida por muitos, sem habilitações específicas, com pouca qualificação e preparação profissional, dando origem à ideia de que "qualquer um pode ser professor" (Jesus, 2004, p.195). Esta imagem de desqualificação da classe docente assenta, também, no facto de muitas pessoas entrarem para a docência, não por vocação, mas por falta de outras opções profissionais (Jesus, 2000).

Concluindo, de acordo com Nóvoa (1995, p. 21), o processo de profissionalização não é linear nem unidirecional, pois, alternam na história dos professores, desde o século XIX, períodos de profissionalização e desprofissionalização, pautados por conflitos de interesses: "a afirmação profissional dos professores é um percurso repleto de lutas e de conflitos, de hesitações e de recuos. (...) A compreensão do processo de profissionalização exige, portanto, um olhar atento às tensões que o atravessam". Vive-se, atualmente, um momento particularmente crítico desse processo de desenvolvimento do grupo profissional, em que se joga a afirmação ou esbatimento da profissionalidade docente, por força de fatores, como a massificação escolar, com a consequente expansão e diversificação dos públicos escolares, a pressão das administrações e dos poderes económicos para uma " funcionarização" acrescida dos docentes. Os professores continuam prisioneiros de uma cultura que se instalou ao longo deste processo e que contradiz a alegada reivindicação de uma maior autonomia e decisão, associadas a um reforço de profissionalidade.

\section{AVALIAÇÃO DE DESEMPENHO DOCENTE}

Segundo Flores e Pacheco (1999), "a avaliação é um instrumento de desenvolvimento pessoal e profissional que reforça o significado de uma acção de melhoria individual centrada na realidade problemática do ensino" (p. 167), ou seja, a avaliação é o meio de desenvolvimento profissional e pessoal partindo do indivíduo como ponto-chave para a melhoria das suas práticas de ensino.

A avaliação de desempenho docente tem diversos objetivos sendo considerada importante para a promoção da qualidade de ensino.

Conforme Alaiz e Gonçalves (2003, p.10), avaliar "significa examinar o grau de adequação entre um conjunto de informações e um conjunto de critérios adequados ao objectivo fixado, com vista a tomar uma decisão". 
A avaliação consubstancia-se, assim, na recolha e tratamento de informação (constituindo o referido), permitindo a comparação com um padrão (o referente) expressando-se essa comparação num juízo de valor que conduz à decisão/ação.

O propósito da avaliação tem vindo a expandir-se: "centra-se nos materiais didácticos utilizados, nos projectos, nos programas, no desempenho dos professores e nas próprias instituições educativas onde trabalham, entre outras áreas de intervenção" (Graça et al., 2011, p. 14).

A avaliação tem como função produzir um juízo de valor sobre um determinado comportamento ou atitude. De acordo com Alves e Machado (2010), esta etapa do processo, em que se tem de produzir um juízo de valor sobre determinado comportamento/atitude, "ainda que meramente técnica, faz com os sujeitos se envolvam directamente com os seus princípios e fundamentos" (p. 100).

A avaliação como um processo de descrição e produção de um juízo de valor, "aparece associada ao termo valor e supõe sempre um juízo" (Graça et al., 2011, p. 17). A mesma autora refere que "a avaliação do desempenho fornece à escola informação que lhe permite promover actividades que conduzam ao desenvolvimento profissional do seu corpo docente" (p. 21), ou seja, o desenvolvimento profissional tem como objectivos aumentar e aprofundar o espírito de equipa entre docentes, superar as suas dificuldades, promover qualidades dos professores e cooperar para uma melhoria da escola.

A prestação de contas é também importante para que se esclareça o que se faz nos dias de hoje nas nossas escolas. Fernandes (2009) afirma que "precisamos de escolas e de professores que vejam a avaliação e a prestação de contas às suas comunidades e à sociedade em geral, como uma oportunidade para refletirem e, repensarem, os seus projectos e suas práticas" (p. 20). Contudo, é preciso ter em conta o modo como a prestação de contas se faz, não podemos simplesmente "deixar que a avaliação vulgarize no pior sentido e se transforme num procedimento de controlo burocrático administrativo, em vez de um poderoso e exigente processo de regulação e melhoria" (Fernandes, 2009, p. 21).

De acordo com Vieira e Moreira (2011, p.8), "no contexto da avaliação do desempenho nas Escolas, a avaliação e a supervisão tendem a instituir-se como mecanismos de conformidade e reprodução, mais do que como estratégias de transgressão e transformação" devido à máquina da avaliação que "pressupõe um controlo centralizado dos sistemas educativos e uma medição da sua qualidade através da definição de objectivos e padrões estreitos e supostamente universais, criando um conflito entre propósitos formativos de desenvolvimento profissional e propósitos sumativos de selecção e progressão na carreira" (Vieira \& Moreira, 2011, p. 8).

Segundo Flores e Pacheco (1999), o sentido do modelo de avaliação docente não depende de questões muito técnicas, mas de uma análise constante da ação da sua profissionalidade. 


\subsection{Para quê avaliar os docentes?}

A avaliação deve ajudar-nos a conhecer e a compreender as realidades para que as possamos transformar e melhorar. (Fernandes, 2009, p. 20).

A avaliação de desempenho docente deve ajudar, sobretudo, os professores a motivarem-se para melhorarem a sua ação profissional, promovendo, conjuntamente, o seu desenvolvimento profissional e a obtenção de competências e aperfeiçoando o seu ensino e a aprendizagem dos alunos.

Segundo Pacheco e Flores (1999, p.177) “o certo é que a avaliação deve servir, quer para as tomadas de decisão relativas à progressão e promoção na carreira, funcionando como elemento de discriminação do desempenho, quer para o reforço do desenvolvimento profissional."

Será que a avaliação pode motivar o docente, sem forçosamente o stressar e meter-lhe medo? É possível mobilizar um professor para o envolvimento nos projetos coletivos e no seu próprio desenvolvimento profissional?

Sabemos, hoje em dia, que a avaliação deve ser posta ao serviço da regulação e de melhoria das práticas pedagógicas e profissionais dos professores. A mudança da cultura das escolas passa por uma avaliação do desempenho docente que tenha em conta alguns princípios para uma avaliação docente mobilizadora de natureza sobretudo formativa e desenvolvimentista (Fernandes, 2009).

Os professores, no entanto, manifestam-se em função do seu "antes" e do seu "agora" profissional. O mal estar docente tem sido uma preocupação.

\section{FINALIDADES DIFERENCIADORAS DA SUPERVISÃO PEDAGÓGICA E DA AVALIAÇÃo}

Supervisão implica interagir, informar, questionar, sugerir, avaliar construtivamente, desenvolver competências, escutar e compreender (SáChaves, 2002; Vieira, 2006; Alarcão \& Roldão, 2008).

A observação de aulas desempenha um papel basilar no melhoramento da qualidade do ensino e da aprendizagem, constituindo uma fonte de inspiração e motivação e um forte incentivador de mudança na escola. Ela pode ser utilizada em vários cenários e com diferentes finalidades, tais como, diagnosticar um problema, encontrar e aferir possíveis soluções para um problema, demonstrar uma competência, buscar formas alternativas de alcançar os objetivos curriculares, aprender, avaliar o desempenho e o progresso, criar metas de desenvolvimento, reforçar a confiança, estabelecer laços com os colegas e partilhar um sucesso (Reis 2011).

As finalidades da supervisão e avaliação são, na perspetiva de alguns autores, obviamente diferentes, na medida em que a supervisão visa promover o desenvolvimento profissional do professor, enquanto a avaliação procura formular juízos sobre a sua competência. Assim, o primeiro aponta 
para um processo de crescimento e desenvolvimento profissional, concentrado na melhoria da ação e do desempenho profissional, ao passo que o segundo procura certificar a competência do professor para o exercício da atividade profissional, com "embate" na progressão da carreira. Naturalmente que, os princípios, o enfoque e posicionamento face à competência profissional são diferentes, assim como a relação que se estabelece entre os participantes e, consequentemente, o modo como o professor encara ambos os processos. Regularmente, as pessoas que realizam estas tarefas são também pessoas distintas, de modo a separar claramente as finalidades das duas atividades, como vimos acima. Ora, não são estas as funções consagradas ao avaliador que a legislação atribui, atualmente, ao docente que exerce funções de supervisor... por outras palavras, a legislação atribui à mesma pessoa funções (quase) irreconciliáveis. As atuais propensões supervisivas inclinam-se para uma conceção democrática de supervisão que realça a importância da reflexão e aprendizagem colaborativa, bem como a capacidade de gerar, gerir e partilhar o conhecimento, visando a criação e sustentação de ambientes promotores da construção e desenvolvimento da autonomia profissional (Sá-Chaves, 2002; Vieira, 2006; Alarcão \& Roldão, 2008).

Reis, (2011) apresenta algumas finalidades da observação de aulas:

\begin{abstract}
Adequar o processo de supervisão às características e necessidades específicas de cada professor.

Estabelecer as bases para uma tomada de decisão fundamentada sobre o processo de ensino e aprendizagem.

Avaliar a adequação das decisões curriculares efectuadas pelos professores e, eventualmente, suscitar abordagens ou percursos alternativos.

Proporcionar o contacto e a reflexão sobre as potencialidades e limitações de diferentes abordagens, estratégias, metodologias e actividades.

Desenvolver diferentes dimensões do conhecimento profissional dos professores." (Reis, 2011, p.10)
\end{abstract}

Referenciando ainda o mesmo autor, a observação formal de aulas é fortemente influenciada pelo modelo de supervisão clínica e abrange a repetição cíclica de uma sucessão de fases:

Uma sessão pré-observação, para conhecimento dos objectivos e das estratégias de ensino, aprendizagem e avaliação prevista para a aula e para negociação dos focos específicos e procedimentos da observação;

A observação da aula;

A análise dos dados recolhidos;

A sessão pós-observação, para discussão e reflexão crítica sobre os acontecimentos observados e identificação de aspectos positivos e aspectos a melhorar; 
A avaliação global do processo, tendo em vista o estabelecimento de acções e metas de desenvolvimento/aprendizagem (Reis, p.15).

Aguiar e Alves (2010) defendem:

"apesar da grande utilidade da observação de aulas, também existem algumas limitações, na medida em que, por um lado, nem tudo poderá ser observado, desde a planificação das aulas, à preparação dos materiais didáticos, aos métodos pedagógicos e ao relacionamento com a comunidade escolar e educativa e, por outro, levanta a problemática da subjetividade do observador" (p.238).

Assim, "a observação é fortemente condicionada por fatores do observador (experiência prévia, expetativas e teorias práticas do ensino e da supervisão...), interessando formar os professores na observação a fim de garantir o seu envolvimento crítico nos encontros anteriores e posteriores às aulas observadas" (Vieira \& Moreira, 2011, p. 31).

Para a observação de aulas é importante definir-se o que é que se vai observar, para depois se deliberar como se vai observar e que técnicas utilizar.

Relativamente à autoavaliação, o mesmo autor refere que "é necessário criar uma imagem construtiva da autoavaliação, vê-la como um instrumento a favor do professor e da sua atuação profissional" onde predominam as funções de prestar atenção e clarificar (p. 23).

Ao entregarem a sua autoavaliação os docentes estão a exercer a sua autonomia apoiada numa reflexão crítica sobre o seu desempenho profissional e simultaneamente a "terem uma palavra ativa e prévia aos juízos avaliativos sobre o seu desempenho profissional". Assim o docente consciencializa-se do que faz e porque o faz, sendo este "muito mais do que um mero exercício de prestação de contas" (Graça et al., 2011, p.96). A autoavaliação neste sentido tem por objetivos:

- O envolvimento do avaliado no processo de avaliação;

- A estimulação da capacidade de auto análise e incentivo à reflexão;

- A consciencialização das suas limitações e o desenvolvimento de estratégias para a sua superação;

- A reflexão sobre a natureza e o tipo de estratégias utilizadas, assim como a sua eficácia;

- A identificação de necessidades de formação.

A definição de objetivos individuais centraliza-se como um elemento fundamental, uma vez que permite a clarificação da contribuição de cada docente na concretização das metas dos principais documentos de "gestão estratégica da escola ou agrupamento de escolas, isto é, no Projeto Educativo e no Plano Anual de Atividades" (Graça et al, 2011, p. 45).

Viegas (2009) afirma que o docente deve "reunir evidências significativas e representativas da sua actividade profissional, com vista à organização de 
um dossiê ou portefólio" (p.180). "O próprio planeamento do processo de avaliação do desempenho tem implicâncias na distribuição de serviço docente que é necessário ter em conta. Identificar e prever tempos comuns para avaliadores e respectivos avaliados" (Morais, 2009, p. 17).

\section{A OBSERVAÇÃO DE AULAS}

A observação de aulas deve ser um processo colaborativo entre o docente e o supervisor. Assim, estes devem " desempenhar papéis importantes, antes, durante e após a observação, de modo a assegurar benefícios mútuos no desenvolvimento pessoal e profissional" (Reis, 2011, p.19).

Neste sentido, a observação de aulas enquadra-se num projeto global de Escola e contribui para o desenvolvimento pessoal e profissional dos docentes, para a melhoria do serviço educativo prestado e para o incremento do trabalho colaborativo, com vista ao sucesso educativo dos alunos.

Segundo Vieira $e$ Moreira (2011, p. 28), "não é possível falar de observação de aulas como estratégia de supervisão e desenvolvimento profissional sem nos referirmos ao modelo de supervisão clínica", sendo este o que "mais resistiu à prova do tempo. Por outro lado, é aquele que "no contexto da avaliação de desempenho pode apoiar a observação de aulas e a reconstrução das práticas dos professores".

O sucesso da observação de aulas depende, segundo Reis (2011), de uma preparação cuidadosa, designadamente, no que diz respeito à definição da frequência das mesmas, à duração, aos focos específicos a observar, à escolha das metodologias a utilizar e à conceção de instrumentos de registo adaptados. O mesmo autor refere que é importante serem observadas aulas em diferentes turmas e em vários dias da semana.

A observação da sala de aula, a gestão da sala de aula, a interação na sala de aula entre professor /aluno, o discurso do professor, o discurso dos alunos, o clima de sala de aula e as atividades pedagógicas, que passam pela diferenciação educativa, são exemplos muito importantes de focos de observação.

Morgado (2003) considera que a diferenciação educativa requer a existência de um modelo que permita analisar as práticas a desenvolver nas salas de aula, modelo esse que se estrutura em torno de seis dimensões fundamentais: "planeamento, actividades /tarefas de aprendizagem, organização do trabalho dos alunos; clima social de sala de aula; materiais e recursos e avaliação" (pp.81-82). O mesmo autor menciona a importância de cada dimensão:

- Planeamento - Envolve a planificação do trabalho a desenvolver. Um percurso bem organizado e estruturado, que se vá realizando por etapas bem definidas, aumenta significativamente os níveis de sucesso para todos os alunos. Os professores definem o que o aluno precisa de aprender, as condições em que vai aprender, como vai aprender e os critérios de avaliação a utilizar; 
- Materiais e recursos de aprendizagem - Refere os materiais e recursos que o professor utiliza como suporte à aprendizagem.

- Organização do trabalho dos alunos - Engloba a forma como os alunos são solicitados a organizarem-se para desenvolverem a aprendizagem.

- Clima social de sala de aula - A sala de aula é o local privilegiado da atividade da turma. Neste contexto, o clima social positivo na sala de aula assume-se como um aspecto fundamental numa organização de escola que desejavelmente se assume como diferenciada.

- Avaliações - Consideram-se nesta dimensão, todos os processos relativos à avaliação do processo de ensino - aprendizagem considerando os procedimentos e mecanismos envolvidos (Morgado, 2003).

O modelo proposto, só poderá conduzir a resultados desejáveis se funcionar na base da observação, da avaliação sistemática, constante, rigorosa e adequada e da reflexão contínua. Estas práticas devem ser objeto de análise colaborativa entre professor e supervisor.

"A observação de aulas constitui, assim, um processo colaborativo entre o professor e o mentor ou supervisor. Ambos devem desempenhar papéis importantes antes, durante e após a observação de forma a assegurar benefícios mútuos no desenvolvimento pessoal e profissional" (Reis, 2011, p. 19).

O modelo clínico (ciclo de avaliação clínica) detém uma dimensão metodológica que continua a dominar a supervisão e a avaliação dos professores. As práticas de supervisão clínica baseiam-se no estudo de situações reais do contexto escolar e recorrem à observação para examinar modelos de conduta em sala de aula e melhorar o ensino através da interação entre professores e supervisores (Alarcão, 2002; Sá Chaves, 2002). Trata-se de um processo de observação, reflexão e ação sobre a prática, em que o observador assume o papel de colega crítico, que funciona como apoio e recurso para a superação das dificuldades que são vividas e sentidas (Alarcão \& Tavares, 2003).

Vieira e Moreira (2011, p.29), salientam as vantagens da "análise colaborativa das práticas de ensino e aprendizagem com o objetivo de as melhorar (...) através de ciclos de observação compostos por três fases principais", ou seja, resume as tarefas que o ciclo de avaliação deve ter: préobservação, observação e pós-observação descrevendo cada uma delas através do seguinte quadro. 


\section{Quadro I}

Tarefas do ciclo de avaliação (adaptado de Vieira \& Moreira, 2011, p. 29)

\begin{tabular}{|c|c|c|}
\hline PRÉ-OBSE & $A C \bar{A} O$ & PÓS-C \\
\hline $\begin{array}{l}\text { Promover um clima relacional facilitador } \\
\text { da construção/negociação de saberes. } \\
\text { Discutir as intençōes e estratégias do } \\
\text { professor relativamente à aula a obser- } \\
\text { var. } \\
\text { Compreender os factores contextuais re- } \\
\text { levantes à observação a efectuar. } \\
\text { Definir objectivos, enfoques e estraté- } \\
\text { gias de observação e distribuir tarefas de } \\
\text { observação entre os observadores. } \\
\text { Desenhar/adaptar instrumentos de ob- } \\
\text { servação, global ou focalizada. }\end{array}$ & $\begin{array}{l}\text { Adoptar um comportamento } \\
\text { discreto, não intrusivo, de } \\
\text { observação. } \\
\text { Recolher informação em fun- } \\
\text { çäo dos objectivos/formas } \\
\text { de observação definidos. } \\
\text { Recorrer a diversas formas } \\
\text { de registo da informação. } \\
\text { Conciliar registos descritivos } \\
\text { com registos interpretati- } \\
\text { vos. } \\
\text {... }\end{array}$ & $\begin{array}{l}\text { Promover um clima relacional } \\
\text { facilitador da construção /nego- } \\
\text { ciação de saberes. } \\
\text { Fornecer feedback informativo } \\
\text { e não ameaçador da auto-esti- } \\
\text { ma/confiança do professor. } \\
\text { Descrever, interpretar, confron- } \\
\text { tar e reconstruir teorias e prá- } \\
\text { ticas. } \\
\text { Encorajar uma atitude indagató- } \\
\text { ria face à prática. } \\
\text { Avaliar o ciclo de observação. } \\
\text {... }\end{array}$ \\
\hline
\end{tabular}

Blumberg, cit. por Vieira e Moreira (2011), menciona a importância da recolha e análise de informação e regulação conjunta da eficácia dos processos supervisivos quanto à obtenção das suas finalidades e à qualidade da relação interpessoal desenvolvida (avaliação sistemática da eficácia).

Do ponto de vista ideológico, supervisão pressupõe: colegialidade, confiança mútua, liberdade, autonomia, espírito crítico. O Professor é ator intelectual e político e o ensino uma forma de debate e luta em torno de ideias e ideais importantes.

A Avaliação de Desempenho Docente deve estar ao serviço da construção de comunidades de desenvolvimento profissional: empreendimento coletivo, interativo, partilha e reflexão sobre sucessos e insucessos, lideranças, informação, apoio e encorajamento.

O perfil do professor atual é o de um profissional preparado com todos os instrumentos necessários (teóricos, técnicos e práticos) que lhe permitam desempenhar uma prática reflexiva e capaz de dar resposta à diversidade de alunos com que é confrontado na escola de hoje e na do futuro. A sua função principal é estimular aprendizagens significativas nos alunos e o seu desenvolvimento integral enquanto indivíduos e cidadãos. Esta é uma função complexa, que exige o desenvolvimento de conhecimentos, capacidades e atitudes a vários níveis, mas que exige, sobretudo, uma grande capacidade criativa e participativa para se adaptar e intervir nos processos de mudança (Alonso, 2005).

De acordo com Graça et al, (2011, p. 29) o "Nível de Desempenho relativamente à Preparação e Organização das actividades letivas" é:

- Excelente - Planificação é correta e coerente científica e pedagogicamente. Capacidade de relacionar com a sua área e outras que, apesar de diferentes, complementam a aprendizagem. Atitude reflexiva 
e autónoma, promoção de estratégias e métodos adequados ao nível etário dos alunos e aos conteúdos programáticos propostos. Atitude sistémica e inovadora (não exclusivamente com recurso TIC).

- Muito Bom - Planificação correta e coerente científica e pedagogicamente. Relacionação de vários saberes que complementam a aprendizagem. Atitude reflexiva e autónoma. Adequação sistemática e diversificação das estratégias ao nível etário dos alunos e aos conteúdos programáticos propostos.

- Bom - Planificação correta e coerente científica e pedagogicamente. Relacionação de saberes que complementam a aprendizagem. Adequação sistemática e diversificação das estratégias ao nível etário dos alunos e aos conteúdos programáticos propostos.

- Regular - Planificação correta e coerente científica e pedagogicamente. Adequação das estratégias e metodologias ao contexto de sala de aula.

- Insuficiente: Planificação com muitas falhas, pouca coerência científica e pedagogicamente, ou até mesmo inexistente. Não adaptação nem diversificação das estratégias, das metodologias e dos recursos utilizados (p.29).

A ficha de registo de observação de aulas é utilizada como o referencial da observação e nela se assinala a avaliação fixa de cada uma das seis competências de lecionação. Este tipo de instrumento apresenta uma relação pormenorizada de comportamentos ou acontecimentos considerados desejáveis, organizados por áreas/dimensões. Coube ao observador "registar a presença de um comportamento ou acontecimento durante a aula (Reis, 2011, p.26).

A grelha refere a componente da sala de aula, os conteúdos, a relação pedagógica com os alunos, tendo sempre como objetivo a melhoria da qualidade do ensino.

Um modelo de instrumento de registo de fim aberto poderá adequar-se, também, a uma fase inicial/exploratória em que se ignorem as competências do professor. Este documento possibilita obter uma ideia do que acontece numa sala de aula através do registo dos principais acontecimentos observados.

"Pretende-se que o mentor ou supervisor registe a maior quantidade de informação possível sobre as actividades realizadas, os métodos de ensino utilizados, as interacções estabelecidas e outros aspetos observados. Neste caso, o registo dos acontecimentos deverá ser efectuado de cinco em cinco minutos, permitindo obter um "retrato" pormenorizado da aula observada" (Reis, 2011, p. 30).

De acordo com Reis (2011, pp. 32, 33) salientamos, similarmente, a importância das listas de verificação, uma vez que "constituem o instrumento de observação mais objectivo e mais fácil de aplicar" e cujos aspetos a observar podem ser os seguintes: 
- A planificação da aula foi seguida?

- Os recursos utilizados eram adequados às actividades propostas?

- Os recursos utilizados eram adequados à idade e às competências dos alunos?

- Houve diferenciação de tarefas de acordo com as necessidades individuais dos alunos?

- O ambiente de sala de aula era promotor de aprendizagens?

- As tecnologias de informação e comunicação foram utilizadas nas actividades realizadas?

- As formas de comunicação eram apropriadas aos objectivos propostos e às características dos alunos?

- O professor demonstrou domínio do conteúdo abordado?

- Houve evidências de que os alunos tenham aprendido?

- Os alunos foram avaliados?

- Os alunos participaram na sua própria avaliação?

- Foram identificadas algumas necessidades de formação?

Antes de proceder à observação da aula, o supervisor deve estar ciente da influência que as suas experiências pessoais, o seu percurso de formação e as suas crenças relativamente ao ensino exercem no processo de observação, nomeadamente nos aspectos que valoriza e nos comentários que poderá efetuar posteriormente. "Um observador eficaz deve reconhecer que as suas observações representam apenas uma versão do que se passou na sala de aula, não constituindo um retrato da realidade" (Reis, 2011, p.22).

No seguimento do que foi referenciado anteriormente, passo, agora a apresentar indicações que temos em linha de conta, aquando das observações de aulas na nossa área - a educação especial.

Os docentes observados são informados acerca do objetivo específico da observação. Assim, o objetivo consiste em ver o modo como cada professor(a) interpreta os conteúdos. Este primeiro contacto vai servir para chegar a um acordo sobre o modo de processar a observação (quando e quem a irá realizar).

O guião que se segue vai ajudar-nos:

Antes de começar a observação: Numa primeira conversa, o professor explica ao supervisor /avaliador o que tem intenção de fazer, quais os seus objetivos, se vai adaptar os materiais de ensino, etc. Deste modo, o observador poderá prever os aspetos mais pertinentes no que respeita os objetivos da observação (particularmente, aqueles que estão relacionados com reflexões. Assim, é importante responder às questões:

1. "Quais são os objectivos que definiu para a aula que irei observar? O que pretende que os alunos aprendam? Como conseguirá saber se os alunos aprenderam?

2 - Que estratégia irá implementar para alcançar os objectivos propostos? Que abordagens e actividades irá propor? Porque escolheu essas 
actividades? Como se articulam essas actividades? Que recursos irá utilizar?" (Reis, 2011, p.23).

Durante a sessão: o observador evita a interrupção do desenvolvimento normal da aula. O seu trabalho consiste em anotar os diferentes aspetos que vai observando.

As indicações do tempo são interessantes em determinados momentos. Anotar a duração das atividades e das situações é muito importante.

No final da aula: conversa-se com o professor para que este possa exprimir o seu sentimento sobre o que se passou durante a aula.

Sintetizando, "o sucesso de uma observação de aula baseia-se na selecção e na adaptação rigorosas dos instrumentos, de acordo com o contexto, as fases do ciclo de supervisão, o foco da observação e as necessidades específicas de cada professor" (Reis, 2011, p.7).

\section{METODOLOGIA}

Na tentativa de definir o conceito de Avaliação do Desempenho Docente, adiante designado ADD, citamos Rodrigues e Peralta (2008) para quem avaliar o desempenho dos professores

"é um processo que implica a observação, a descrição, a análise, a interpretação da actividade profissional (...). Avaliar é saber, por inferência, através da observação da sua actividade no local de trabalho se, e em que medida, os professores adquiriram e desenvolveram as competências consideradas como integrando os referentes da avaliação (...) como constam do perfil de desempenho, do currículo nacional dos alunos, do projeto local de escola e do plano individual do professor" (p.11).

A observação de aulas integra-se no princípio do acompanhamento científico, pedagógico e didático dos professores, contribui para fomentar o trabalho colaborativo na atividade docente, reforçando a cultura de avaliação interpares, e criando condições para uma melhoria do desempenho profissional.

O que faz de alguém um bom professor?

Esta é uma questão que já fez correr rios de tinta mas poucos resultados práticos tem vindo a ter. Bem sei que para avaliar e ser avaliado tenho que me avaliar! (Vieira \& Moreira, 2011, p.46). Então, que juízos de valor temos para exteriorizar acerca da avaliação de professores?

Num contexto de mudança do sistema educativo surge a avaliação de desempenho docente. Assim, a ideia deste trabalho assenta, fundamentalmente, nos seguintes pressupostos:

- interesse pessoal e profissional pela avaliação de desempenho docente

e supervisão pedagógica (observação de aulas e práticas educativas). 
- O facto de nos depararmos com experiências onde a validade, credibilidade, utilidade, transparência e equidade, valores de cultura, de cooperação e entre ajuda não estão subjacentes a todas as práticas da escola.

\section{Objetivos}

A responsabilização no atendimento a todos os alunos por parte do professor exige uma melhoria e uma consequente mudança nas suas práticas pedagógicas que acabam por beneficiar a todos (Porter, 1997). Neste seguimento, considera-se que o Homem é orientado por objetivos, uns gerais outros específicos. Assim, estes devem ser expressos de uma forma clara e apreciável uma vez que se não for assim, não nos referimos a objetivos mas a desejos (Quivy \& Campenhoudt, 1998). Neste sentido os objetivos deste trabalho são:

- Conhecer a opinião de alguns professores sobre o atual modelo da

Avaliação do Desempenho Docente.

- Identificar pontos fortes e fracos no atual modelo de Avaliação do Desempenho Docente.

-Conhecer a importância da observação de aulas no processo de Avaliação de Desempenho Docente.

\section{Tipo de investigação}

Para a realização deste pequeno estudo optou-se por uma investigação qualitativa, através da realização de uma entrevista. Com este tipo de pesquisa é possível averiguar as perspetivas dos inquiridos.

\section{Amostra}

A amostra é um subconjunto de uma população, ou seja, uma réplica em miniatura da população (Fortin, 1999). Desta forma, a nossa amostra é constituída por 6 professores do $2^{\circ}$ e $3^{\circ}$ Ciclos pertencentes a um Agrupamento de Escolas do concelho de Viseu.

Os entrevistados são do sexo feminino e com idades compreendidas entre os quarenta e quarenta e os cinquenta e cinco aproximadamente. No que concerne ao tempo de serviço, os entrevistados situam-se entre os quinze e os trinta anos de tempo de serviço.

\section{Entrevista}

A problemática da avaliação de desempenho, enquanto objeto de questionamento e análise, reúne uma importante produção de conhecimento. É nesse sentido que se colocam as interrogações que, num momento inicial, enunciam a nossa curiosidade investigativa. Assim, elaboramos um guião de entrevista com as seguintes questões:

1- Qual a sua opinião sobre o atual modelo da Avaliação de

Desempenho Docente?

2 - O que considera como pontos fortes e fracos no atual modelo de

Avaliação do Desempenho Docente? Justifique a sua resposta.

3 - Qual a importância da observação de aulas no processo de Avaliação de Desempenho Docente? 
Relativamente às questões abertas proceder-se-á à realização de uma breve análise de conteúdo. Nesta técnica, escolhe-se a palavra-chave que designará a categoria e as subcategorias que especificam as características da categoria (Amado, 2000). Este procedimento, de acordo com Ribeiro (2009), consiste numa técnica para fazer inferências através da identidade sistemática e objetiva das características específicas de uma mensagem.

As linhas que se seguem destinam-se à apresentação das informações consideradas mais significativas e pertinentes. A subdivisão em categorias (macrocategorias) e subcategorias (microcategorias) baseou-se nas características inerentes ao próprio estudo.

\section{RESULTADOS}

O Quadro concetual geral representado apresenta a categoria: conceções sobre a avaliação de desempenho docente / observação de aulas.

\section{Quadro II}

Quadro concetual da avaliação de desempenho docente

\begin{tabular}{|c|c|}
\hline Categorias (Macrocategorias) & Subcategorias (microcategorias) \\
\hline & - Opiniões sobre a ADD \\
Conceções sobre a ADD & - Pontos fortes da ADD \\
& - Pontos fracos da ADD \\
& - Importância da observação de aulas no \\
& processo de ADD \\
\hline
\end{tabular}

\section{Quadro III}

Subcategoria opiniões sobre a ADD

\begin{tabular}{|c|c|}
\hline Subcategorias & Relatos dos professores \\
\hline - Processo burocrático & (...) "é burocrático." (2 prof) \\
\hline - Cria desigualdade & $\begin{array}{l}\text { (,...) "na parte burocrática e leva a que } \\
\text { haja } \\
\text { desigualdades" (3prof.) }\end{array}$ \\
\hline $\begin{array}{l}\text { - Desacordo em relação às entidades } \\
\text { avaliadoras }\end{array}$ & $\begin{array}{l}\text { (...) "os critérios de avaliação variam de } \\
\text { agrupamento para agrupamento, em que } \\
\text { alguns docentes preenchem todas as } \\
\text { vagas, portanto, de Muito Bom, de } \\
\text { Excelente e noutros agrupamentos a } \\
\text { classificacaca usada pelo menos é de } \\
\text { Bom. Não utilizam as restantes menções } \\
\text { qualitativas" (2prof). } \\
\text { (...)" a avaliação deve ser feita por } \\
\text { alguém externo à escola" ( } 6 \text { prof.) }\end{array}$ \\
\hline
\end{tabular}




\section{Maria Deolinda Oliveira Silva}

Como se pode aferir no quadro 3, no que concerne às opiniões sobre a ADD recolhidas junto dos inquiridos, verifica-se que cinco referem ser um processo burocrático, três referem ser desadequado à realidade dos professores, o qual provoca injustiças devidas a diversidade de critérios de avaliação. Todos consideram, também, que a avaliação deve ser feita por alguém externo à escola.

Quadro IV

Subcategoria pontos fortes da ADD

\begin{tabular}{|l|l|}
\hline Subcategorias & Relatos dos professores \\
\hline - Proporciona reflexão & $\begin{array}{l}\text { (...) “tem como ponto forte, obrigar-nos } \\
\text { a refletir } \\
\text { sobre aquilo que fazemos" ( } 6 \text { prof.). }\end{array}$ \\
& $\begin{array}{l}\text { (..) é positiva se for realizada e } \\
\text { analisada por uma equipa especializada } \\
\text { (6 prof.). }\end{array}$ \\
\hline
\end{tabular}

De acordo com o quadro 4, como pontos fortes todos os inquiridos opinam: "Como ponto forte achamos que nos obriga a refletir sobre aquilo que fazemos" e que é positiva se for realizada e analisada por uma equipa especializada.

\section{Quadro V}

Subcategoria pontos fracos da ADD

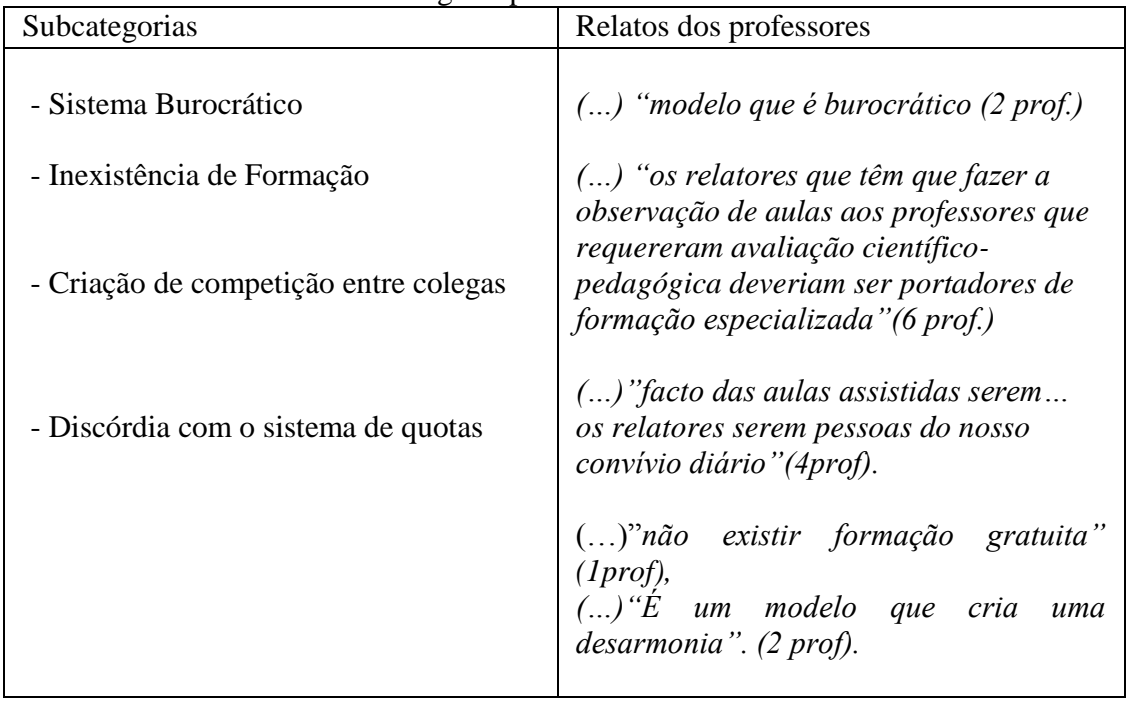

Como se pode verificar no quadro 5, os pontos fracos manifestados foram: "ser um modelo burocrático; a obrigação de fazer formação e não existir gratuitamente; o sistema de quotas que faz com que haja injustiças; os relatores que têm que fazer a observação de aulas aos professores que 
requereram avaliação científico-pedagógica deveriam ser portadores de formação especializada; É um modelo que cria uma desarmonia".

É fundamental destacar o facto de os professores referirem que a formação especializada em avaliação de desempenho docente é o mais urgente neste momento. Este aspeto é distinguido também por Amelsvoort e colaboradores (2009), quando dizem que "há necessidade de realizar um maior investimento na formação em competências de avaliação e "garantir aos formadores condições para adquirirem conhecimentos e competências de avaliação mais abrangentes, nomeadamente a partir do contacto com as teorias, metodologias e práticas de avaliação internacionalmente reconhecidas" (p. 8).

Graça e colaboradores (2011) afirmam que a formação não poderá estar ausente. Ela é um eixo estratégico para preparar avaliadores e avaliados e apoiar durante o processo de avaliação.

\section{Quadro VI}

Subcategoria Importância da observação de aulas no processo de ADD

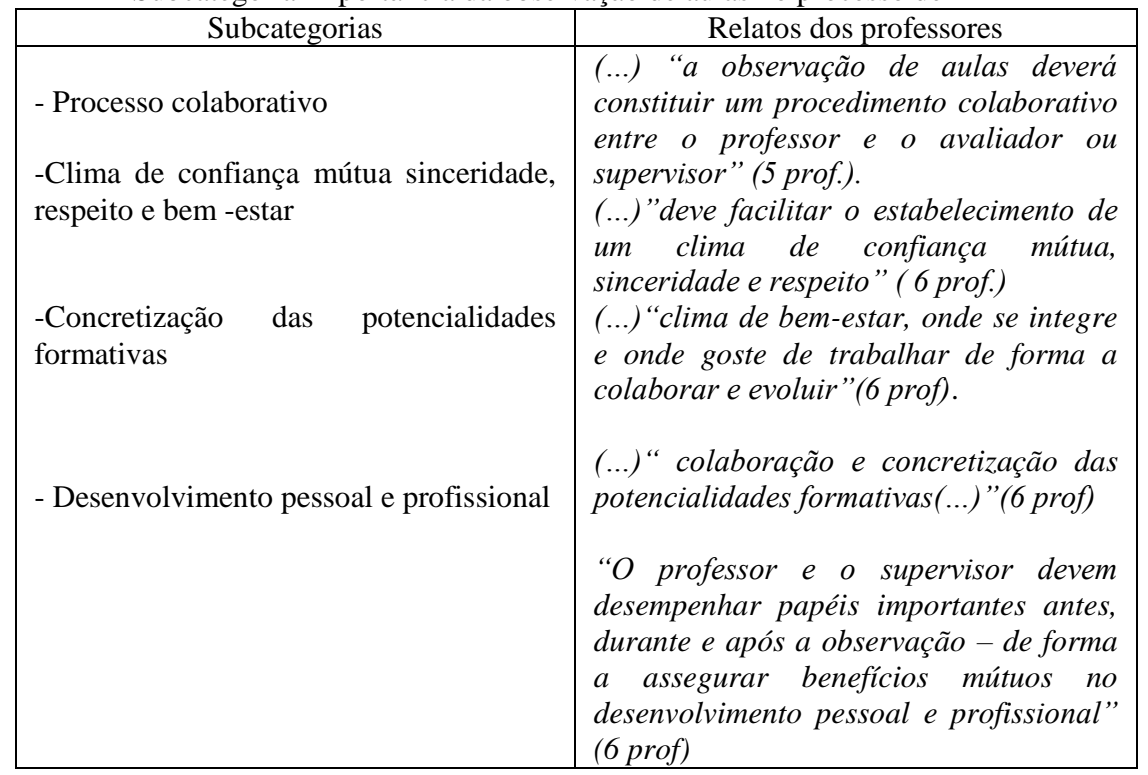

Através da leitura e análise do quadro 6, verifica-se que os seis inquiridos referem que "a observação de aulas deverá constituir um processo colaborativo entre o professor e o mentor ou supervisor. Ambos devem desempenhar papéis importantes - antes, durante e após a observação, de forma a assegurar benefícios mútuos no desenvolvimento pessoal e profissional. A colaboração nas diferentes fases do processo facilitará o estabelecimento de um clima de confiança mútua, sinceridade e respeito, 
clima esse decisivo para a concretização das potencialidades formativas da observação de aulas".

Santos (2007) afirma que os problemas da avaliação dos professores só podem ser evitados ou solucionados, em primeiro lugar, criando um sistema de avaliação de qualidade, útil, credível e tecnicamente impecável.

Um sistema de avaliação só servirá se for aceite pelos docentes e por toda a comunidade educativa", para que o docente sinta um clima de bem-estar, onde se integra e onde gosta de trabalhar de forma a colaborar e evoluir.

Aguiar e Alves (2010) vêm ao encontro das opiniões destes professores quando referem que "como tem vindo a ser referido, os professores estão preocupados com o clima geral da escola. Este deverá melhorar e contribuir para uma melhor prestação dos docentes. Apesar de os professores concordarem que é necessário um sistema de avaliação, não concordam com a forma como este está a ser implementado. Consideram-no injusto e pouco exequível, por isso estão desmotivados e preocupados com a deterioração do clima das escolas/agrupamentos" (p. 252).

Alguns professores consideram que as entidades avaliadoras deveriam ter uma formação própria para exercer a função de observador de aulas.

Um avaliador deve ter conhecimentos e experiência em avaliação, aplicação de instrumentos e elaboração de relatórios informativos (Santos, 2007).

De acordo com o Decreto Regulamentar n. ${ }^{\circ}$ 26/2012 de 21 de fevereiro (p.885):

a experiência colhida com modelos de avaliação do desempenho docente anteriores demonstrou a necessidade de garantir um modelo de avaliação que vise simplificar o processo e promova um regime exigente, rigoroso, onde se valorize a actividade lectiva e se criem condições para que as escolas e os docentes recentrem o essencial da sua actividade: o ensino e a aprendizagem".

A avaliação externa é centrada na observação de aulas e no acompanhamento da prática pedagógica e científica do docente. Para este efeito, é constituída uma bolsa de avaliadores, formada por docentes de todos os grupos de recrutamento.

Todas as professoras questionadas aludem que "a observação de aulas deveria ser feita por uma equipa especializada" (...) "um sistema de avaliação só servirá se for aceite pelos docentes e por toda a comunidade educativa, para que o docente sinta um clima de bem-estar, onde se integra e onde gosta de trabalhar de forma a colaborar e evoluir".

Referem que " a observação de aulas deverá constituir um processo colaborativo entre o professor e o mentor / supervisor / avaliador. Ambos devem desempenhar papéis importantes - antes, durante e após a observação, de forma a assegurar benefícios mútuos no desenvolvimento pessoal e profissional.

Indo ao encontro do referenciado pelos entrevistados, Santos (2007) afirma que os problemas da avaliação dos professores só podem ser evitados 
ou resolvidos criando um sistema de avaliação de qualidade: útil e credível. Em segundo lugar, criar uma cultura de avaliação, através de um modelo mais profissional e menos burocrático onde o docente perceba que a avaliação existe para o ajudar no seu trabalho.

Um sistema de avaliação só servirá se for aceite pelos docentes e por toda a comunidade educativa, para que o docente sinta um clima de bem-estar, onde se integra e onde gosta de trabalhar de forma a colaborar e evoluir.

\section{CONCLUSÃO}

Em suma, tal como aponta o relatório sobre o acompanhamento e a monitorização da avaliação do desempenho associada ao Conselho Científico para a Avaliação de Professores (2009), destacam-se os seguintes efeitos negativos provocados pela Avaliação de desempenho docente no clima de escola: instabilidade, conflito interno, conflito externo, desmotivação dos docentes, insatisfação dos docentes e aumento da competitividade entre os mesmos.

O artigo 3. ${ }^{\circ}$ do Decreto Regulamentar n..$^{\circ}$ 26/2012, de 21 de fevereiro, vem referir que a avaliação do desempenho do pessoal docente visa a melhoria da qualidade do serviço educativo e da aprendizagem dos alunos, bem como a valorização e o desenvolvimento pessoal e profissional dos docentes.

Desta forma, a avaliação será uma oportunidade de desenvolvimento e de satisfação dos professores, com importantes reflexos na qualidade do seu trabalho pedagógico e, consequentemente, na aprendizagem dos alunos.

É importante ter em linha de conta que a avaliação tem como função produzir um juízo de valor sobre um determinado comportamento ou atitude. De acordo com Alves e Machado (2010), esta etapa do processo, em que se tem de produzir um juízo de valor sobre determinado comportamento/atitude, "ainda que meramente técnica, faz com os sujeitos se envolvam directamente com os seus princípios e fundamentos" (p. 100).

Para Flores e Pacheco (1999),"o professor é um adulto que se encontra num processo contínuo de aprendizagem, a sua avaliação não significará mais do que a problematização constante do seu múltiplo processo de desenvolvimento, através de instrumentos de análise do conhecimento profissional que adquire e utiliza. Deste modo, o desenvolvimento profissional entende-se como um processo contínuo de aprendizagem que inclui, por um lado, a aquisição de novas competências, resultantes de práticas de inovação escolar e, por outro, a consolidação de competências adquiridas e mantidas ao longo da carreira" (p. 168).

O desenvolvimento profissional pode fruir da combinação de três elementos-chave: a comunicação, o comprometimento organizacional e a colaboração. Também o rigor, a adequação ética, a exequibilidade e a utilidade são critérios que devem orientar o processo de avaliação. 
Uma das competências mais expressivas do supervisor é a sua capacidade de observação, pois todos nós observamos situações diferentes num cenário de supervisão.

A observação de aulas como projeto de Escola, integrada num ciclo de supervisão pedagógica, tem como referentes internos o projeto educativo, os projetos curriculares de Escola e turma e o plano de atividades. São estes referentes que dão sentido à observação de aulas.

\section{BIBLIOGRAFIA}

Aguiar, J. \& Alves, M. (2010). A Avaliação do desempenho docente: tensões e desafios na escola e nos professores. In Maria Palmira Alves e Maria Assunção Flores. Trabalho Docente, Formação e Avaliação: Clarificar conceitos, fundamentar práticas (pp. 229-258). Mangualde: Edições Pedagogo.

Alarcão, I. (2001). Compreendendo e construindo a profissão de professor. Aveiro: Universidade de Aveiro.

Alarcão, I. (2002). Escola reflexiva e desenvolvimento institucional: Que novas funções supervisivas? In J. Oliveira - Formosinho (Org.), Supervisão na formação de professores (pp. 217-238). Porto: Porto Editora.

Alarcão, I. \& Tavares, J. (2003). Supervisão da prática pedagógica. Uma perspectiva de desenvolvimento e aprendizagem (2. ${ }^{\text {a }}$ ed. revista e actualizada). Coimbra: Almedina.

Alarcão, I. e Roldão, M. C. (2008). Supervisão: um Contexto de Desenvolvimento Profissional dos Professores. Mangualde: Pedago.

Alaiz, V. \& Gonçalves, C. (2003). Auto-avaliação de Escolas - Pensar e Praticar. Teoria, Guias Práticos. Porto: Edições ASA.

Alves, P. \& Machado, E. (2010). Para uma "política" de avaliação do desempenho docente: desenvolvimento profissional e auto-avaliação. In Palmira Alves e Eusébio Machado. O pólo de excelência. Caminhos para a Avaliação do Desempenho Docente(pp. 89-106). Porto: Areal Editores.

Alonso, L.; \& Roldão, $\mathrm{M}^{\mathrm{a}} \mathrm{C}$ (Coord.) (2005) Ser Professor do $1^{o}$ Ciclo: Construindo a Profissão, Coimbra: Ed. Almedina.

Amado, J. (2000). A técnica de Análise de Conteúdo. Revista Referência da Escola Superior de Enfermagem de Coimbra, $n^{\circ} 5$, 53-60.

Conselho Científico para a Avaliação de Professores (2010). Relatório sobre o acompanhamento e a monitorização da avaliação do desempenho docente na rede de escolas associadas ao CCAP. Lisboa: Ministério da Educação.

Cunha, A. (2008). Ser professor. Braga: Casa do Professor.

Fernandes, D. (2009). Para uma avaliação de professores com sentido social e cultural. Revista do Centro de Formação Francisco de Holanda. Avaliação do Desempenho Docente, 16, 19-23. 
Flores, M. \& Pacheco, J. (1999). Formação e Avaliação de Professores. Porto: Porto Editora.

Fontes, C. (s.d.). Modelos de formação de professores em Portugal. Acedido em $2^{\circ}$ de dezembro de 2011, em http://educar.no.sapo.pt/modelos.htm

Fortin, M. (1999). O Processo de Investigação. Da concepção à realização. Loures: LUSOCIÊNCIA.

Graça, A., Duarte, A., Lagartixa, C., Tching, D., Tomás, I., Almeida, J., Diogo, J.,Neves, P. \& Santos, R. (2011). Avaliação do Desempenho Docente Um Guia para a Ação. Lisboa: Lisboa Editora.

Jesus, S. (2000). Motivação e formação de professores. Coimbra: Quarteto.

Jesus, S. (2004). Desmotivação e crise de identidade na profissão docente. Katálysis, v. 7, n², 192-202. Acedido em 5 de janeiro de 2012.

Loureiro, C. (2001). A docência como profissão. Porto: Asa Editores.

Montero, L. (1999). Professorado de secundária: Una identidad Professional amenazada? Santiago de Compostela: Universidade de Santiago de Compostela.

Morais, J. (2009). A Avaliação de Desempenho dos Docentes - Uma ferramenta ao serviço da gestão. Revista do Centro de Formação Francisco de Holanda. Avaliação do Desempenho Docente, 11-18.

Morgado, J. (2003b). Qualidade, Inclusão e Diferenciação Pedagógica. Lisboa: Instituto Superior de Psicologia Aplicada.

Nóvoa, A. (1995). Profissão professor (2 ${ }^{\mathrm{a}}$ edição, p. 21). Porto: Porto Editora.

Nóvoa, A. (1997). Formação de professores e profissão docente. In A. Nóvoa (Coord.), Os professores e a sua formação ( $3^{\mathrm{a}}$ Edição, pp. 15-33). Lisboa: Publicações D. Quixote.

Nóvoa, A. (1999). O passado e o presente dos professores. In A. Nóvoa (Org.), Profissão professor (2a edição, pp. 13-34). Porto: Porto Editora.

Pacheco, J.A \& Flores, M.A .(1999). Formação e avaliação de professores. Porto: Porto Editora.

Reis, F. A. G. (1999). Avaliação do Desempenho e Identidade Profissional Docente. Dissertação de Mestrado em Educação. Faculdade de Psicologia eCiências de Educação. Universidade do Porto.

Ribeiro, C. (2009). Análise de Conteúdo. Sebenta da Unidade Curricular: Metodologias de Investigação em Educação do Curso de Mestrado em Ciências de Educação - Especialização em Educação Especial, Universidade Católica Portuguesa - Pólo de Viseu.

Rodrigues, A. \& Peralta, H. (2008). Algumas considerações a propósito da avaliação do desempenho dos professores. Ministério da Educação: DGRHE.

Sá-Chaves, I. (2002). A Construção de Conhecimento pela Análise Reflexiva da Praxis. Lisboa: Fundação Calouste Gulbenkian e Fundação para a Ciência e Tecnologia. 
Santos, J. (2007). Entrevista a Javier Murillo (Unesco) - Avaliação dos professores. s.1. s. e. (http://jbarbo00.blogspot.com/2007/10/entrevistajavier-murillo-unesco.html Consultado em 11 de junho de 2012 pelas 18:30 horas)

Sousa, J. (2000). O professor como pessoa. Porto: Asa Editores.

Stronge, J. (2010). O que funciona, de facto, na avaliação de professores: breves considerações. In Assunção Flores. A avaliação de professores numa perspectiva internacional (pp. 24-40). Porto: Areal Editores.

Viegas, H. (2009). Avaliação do Desempenho Docente: Um novo enquadramento para o exercício do ensino. Revista Portuguesa de Pedagogia 43-2, 173 - 199.

Vieira, F. (2006). Formação reflexiva de professores e pedagogia para a autonomia: para a constituição de um quadro ético e conceptual da supervisão pedagógica. In F. Vieira; M. A. Moreira; I. Barbosa; M. Paiva \& I. S. Fernandes, No Caleidoscópio da Supervisão: Imagens da Formação e da Pedagogia. Mangualde: Pedago, pp. 15-44.

Vieira, F. \& Moreira, M.A. (2011).Supervisão e avaliação do desempenho docente. Para uma abordagem de orientação transformadora. Conselho cientifico para a avaliação de professores. Ministério da educação 